\section{Knowledge for conservation-new technology, new players and a new approach}

In 1972, in Stockholm, the first global inter-governmental conference on the environment took place. Many initiatives sprang from that meeting, and from the Earth Summit held 20 years later. Now, as we approach Stockholm +30 and Rio +10 , many commentators and analysts are looking at what has been achieved and at what future environmental strategies might be needed.

Any environmental strategy is only as good as the intelligence and data that have gone into it. The key requirements are an assessment of the overall environmental needs and opportunities (the demand side) and an evaluation of the capacity and ability of organizations and institutions to meet those needs (the supply side). In planning a strategy for conservation and sustainable utilization of biodiversity, we need to take a long, cool look at these elements if we are to come up with plans that will make a difference.

The state of knowledge of biodiversity has been succinctly assessed in a recent publication called Global Biodiversity: Earth's Living Resources in the 21st Century (Groombridge \& Jenkins, 2000). Here we learn that our own species has become extraordinarily successful, taking up 40 per cent of terrestrial productivity. In terms of biomass, we have only one near contender for the top slot-Antarctic krill! The difference is that while krill sustain many other species, we tend to have the opposite effect-the list of extinct species in the book runs to eight pages and the authors argue (conservatively, some might think) that extinction rates are 100-200 times higher than the background rate.

Despite the wealth of new data, it remains a fact that available biodiversity information is inadequate for planning purposes. As a recent example, primates, one of the best known of all animal groups, have recently found their 275 species divided into 310 , based on genetic analysis (unpublished data from Conservation International/International Union for Conservation of Nature (IUCN)/Center for Environmental Research and Conservation, Columbia University meeting, 5 April 2000). Six species of bushbabies are now believed to represent some 40 distinct species, while the gorilla, an icon of conservation, is now split into two species and five subspecies. Such new information can have major impacts on conservation plans. In the absence of complete and empirical data, many conservation organizations use surrogate indicators to identify priorities based on what they consider to be important. The result is an inconsistent array of global analyses that decisionmakers in governments and the private sector often find confusing. At the national level too, conflicting or lack of available data often frustrates the preparation of conservation strategies and action plans.

How may we improve the quality, accessibility and usefulness of data about the living world? Three examples present themselves: use of new technology to build capacity for biodiversity knowledge management in the developing world; engagement of new sources of data; and harmonization of official data deriving from inter-governmental biodiversity-related treaties.

\section{New technologies}

The Internet and World Wide Web have connected computers and databases across the world. This is one aspect of globalization that could benefit conservation, but the opportunity has yet to be fully exploited. As an illustration of this, the United Nations Environment Programme-World Conservation Monitoring Centre's (UNEP-WCMC) Web site, launched in September 1994, now receives 205,000 visitors per month, making 2.4 million hits and extracting more than 20 gigabytes of data. This dwarfs the deliveries that can be made through traditional channels. Whilst many users are from North America and Europe, the spread is truly global, with almost 100 countries receiving support. Of course, not every country in the world can access the Internet easily. The development aid community should be encouraged to assist in this respect, as part of an integrated programme of poverty alleviation and resource conservation. The Internet is the most powerful technology available for empowerment and capacity building in the less-developed nations, and can help everyone to access the data they need for conservation planning and action.

\section{New players}

In the 1970s, knowledge about the living world tended to reside in academia and the non-governmental sector (including museums, botanic gardens and conservation non-governmental organizations (NGOs)). They continue to play a vital role, but we can also see the potential for new contributors, able to communicate through Internet technology. The private sector is the world's biggest force for change, and harnessing their support for conservation and sustainable development is essential. The oil, gas, mining, pharmaceutical, fishery and forestry industries have extensive information 
resources that could and should be mobilized for conservation purposes, but difficulties over intellectual property, communication and perceived competitive advantage have prevented full engagement. In a radical new proposal, BP-Amoco and Rio Tinto are working with UNEP-WCMC to create a public access portal to their environmental datasets. Through demonstrating what might be achieved, these three partners aim to attract other multinational companies to join in.

In many countries of the world, demographic patterns are changing and opportunities for civil society to contribute to environmental monitoring are growing. People are living longer, more active lives and have the potential to make direct observations on the living world around them. Schoolchildren too are interested in monitoring their environment. Database technology tends to channel data providers into tightly controlled and structured systems that are inaccessible to civil society. At UNEP-WCMC, we are seeking support from foundations to help us turn this paradigm on its head, to enable us to welcome new data from any source and in any form. The challenge is in 'managing the chaos' and in finding ways to sustain quality, but the benefit will be a highly motivated army of eyes and ears for conservation.

\section{Harmonizing official data}

Since the 1970s, nations world-wide have signed up to treaties to conserve biodiversity. Conventions on trade in endangered species, on migratory species, wetlands, World Heritage sites, regional seas, as well as European and other regional directives of various kinds, all require official reports on biodiversity and its components. The effort is huge, but the benefits are not. By looking at reporting needs in the round, UNEPWCMC is promoting a 'modular' approach that would allow thematic reports to serve many different purposes. For example, detailed reports on protected areas prepared at the national level once every couple of years could serve World Heritage, Ramsar, Regional Seas and many other purposes. Saving on duplication would allow more resources to go to where they are really needed, in the assessment of biodiversity and in taking direct conservation action.

In conclusion, our knowledge about the living world is sufficient to know that we are losing it, and fast, but is inadequate to ensure that the actions we take in mitigation are focused and effective. We must recognize, and tap into, new sources of relevant data. Making use of Internet technology, engaging people in all walks of life, and taking common-sense steps to maximize the effectiveness of the official assessment and early warning programmes will all help to improve the prospects for the living world upon which we all ultimately depend.

Mark Collins, PhD MBA, Director

UNEP World Conservation Monitoring Centre,

219 Huntingdon Road,

Cambridge CB3 ODL,

UK.

Fax: + 441223277136 ;

e-mail: mark.collins@wcnc.org.uk

At a ceremony at Cambridge on 3 July 2000, Dr Klaus Töpfer, Executive Director of the United Nations Environment Programme (UNEP), announced that the World Conservation Monitoring Centre (WCMC) had joined UNEP as its world biodiversity information and assessment centre. The Rt Hon Michael Meacher MP, Minister for Environment, and Peter Hain, Minister of State for Foreign and Commonwealth Affairs, explained that this development had the full support of the UK Government, as well as the encouragement of WCMC's former partners, IUCN and WWF. WCMC will work closely with UNEP's Division of Environmental Information Assessment and Early Warning, and Division of Environmental Conventions, headquartered in Nairobi, Kenya, as well as the UNEP Regional Offices and networks. This union will not only strengthen the Centre's work in providing global information services on biodiversity, but will also enhance its efforts to build the capacity of nations around the world in implementing multilateral environment agreements.

\section{Reference}

Groombridge, B. \& Jenkins, M.D. (2000) Global Biodiversity: Earth's Living Resources in the 21st Century. World Conservation Press, Cambridge, UK.

Note: This publication will be reviewed in the October 2000 issue of Oryx.

\section{Letter from the editor}

I would like to introduce myself as the new Editor of Oryx - The International Journal of Conservation. Dr Jacqui Morris stepped down as Editor of the journal at the end of 1999, after 18 years in the post. Her contribution and commitment over that time was invaluable and I would like to take this opportunity to thank her for all that she has done for the journal. It is a great honour and privilege to have been appointed as editor of Oryx.

Over the next few months, I will be working closely with the team of senior editors to review the content and focus of Oryx and to plan for its future development. Details of any changes will be notified in forthcoming issues of the journal. I also intend to publish an annual editor's report in the January issue of Oryx; this report will not only 